\title{
Elasto-Damage Constitutive Modelling of Recycled Aggregate Concrete
}

\author{
Asad-ur-Rehman Khan 1, a), Fatima Khalid ${ }^{1, \text { b) }}$ and Shamsoon Fareed ${ }^{1, c)}$ \\ ${ }^{l}$ NED University of Engineering and Technology, Pakistan
}

\begin{abstract}
Use of recycled aggregates in concrete has proved to be beneficial in attaining sustainable construction without compromising overall material and structural performance when compared with concrete containing natural aggregates. However, use of the recycled aggregates in concrete have resulted in reduction in compressive and tensile strengths with the recycled aggregates percentage increase in concrete. Furthermore, it is important to note that most of the finite element software used in the construction industry use concrete model derived from the test results of the conventional concrete, therefore, they may not always predict safe solution for recycled aggregates concrete (RAC). Therefore, in this investigation elasto-damage, proposed by Khan and Zahra, for natural aggregate concrete (NAC) was modified to incorporate the influence of recycled aggregates on the behaviour of concrete. Model use four parameters $\alpha, \beta, \gamma$ and critical energy release rate $\left(R_{c}\right)$ to predict the behaviour of recycled aggregate concrete for multi axial stress states. Parameters $\alpha, \beta$ and $\gamma$ are used to predict the different behavior of concrete in tension and compression while $R_{c}$ controls the damage growth rate. These parameters are defined as a function of concrete compressive strength $\left(f_{c}{ }^{\prime}\right)$ and its initial elastic modulus $\left(E_{o}\right)$. Existing test results for uniaxial compressive state of stress were used to validate this model and it was found that it predicts better post cracking and post peak-behaviour of RAC as compared to the commercially available models for conventional concrete.
\end{abstract}

Keywords:

\section{INTRODUCTION}

The rapid increase in urbanization in countries lead to increase in construction works. Large amount of demolished concrete is wasted every year ultimately filling the landfills. Almost $85 \%$ of the world waste is disposed to landfills. Construction and Demolition (C\&D) waste contributes $13-30 \%$ to the total waste being disposed to landfill $[1,2]$. Asian countries are the major contributor to $\mathrm{C} \& \mathrm{D}$ waste as they produced over half of the world's concrete [3]. To conserve the natural resources and reduce waste landfills, recycled coarse aggregates are used replacing part of natural aggregates from the normal concrete. It has already been proved that recycled aggregates concrete is beneficial to be use in structural applications with some mesures [4]-[5].

Extensive experiments were conducted worlwide and it was concluded that increase of recycled coarse aggregate in concrete reduces its compressive [6] and tensile strength [7]. For theoretical and numerical analysis, the modeling of stress-strain curve plays an important part. Numerous constitutive model were proposed in past to predict the behaviour of RAC in terms of stress-strain curves. Xiao, Li and Zhang [8] has proposed analytical expression for stress-strain curve for RAC by introducing parameters to modify the initial elastic modulus and area under the descending branch after ultimate stress is attained depending on RCA replacement percentages. The curve predicted by this method consist of ascending and descending branch such that if higher percentage of RAC is used then the proportion of plastic deformation in the predicted stress strain curve will also be higher, however, with lower ductility and steeper descending portion.. Ting, Weihong, Zhongxin, Huaili and Taiping [9] modified model proposed by [8] by introducing additional parameters and modifying descending branch equation. Folino, 
Xargay and Vega [10] proposed constitutive model for RAC by using a performance dependent model to predict nonlinear behaviour of RAC. $\mathrm{Hu}, \mathrm{Lu}$ and Cheng [11] performed nonlinear analysis of the RAC columns subjected to cyclic loading by proposing uniaxial damaged plastic constitutive relationship for RAC within the continous thermodynamic framework.

In this study, influence of the recycled aggregates has been incorporated in an elasto-damage model initially proposed by Khan and Zahra [12] for predicting the behaviour of concrete subjected to uniaxial state of stress.

\section{BASICS OF CONSTITUTIVE MODEL}

Khan and Zahra [12] proposed Elasto-damage model based on fundamental surfaces defined by [13] and given in (1)-(3).

$$
\begin{aligned}
& f=\left(R_{i} R_{i}\right)^{1 / 2}-R_{d} / b=0 \\
& F=\left(R_{i} R_{i}\right)^{1 / 2}-R_{c}=0 \\
& f_{o}=\left(R_{i} R_{i}\right)^{1 / 2}-R_{o}=0
\end{aligned}
$$

where, $f$ is the loading function surface, $F$ is the bounding surface, $f_{o}$ is a limit fracture surface defined in terms of thermodynamic force conjugates, $R_{i}$ and critical energy release rate $R_{c}$.

Four model parameters, $\alpha$ (for tensile stress states), $\beta$ (for compressive stress states), $\gamma$ (for volumetric change) and $R_{c}$ critical energy release rate), are used in the model to capture the behaviour of concrete for multiaxial state of stress. Parameters $\alpha, \beta, \gamma$ and $R_{c}$ are used to control the damage growth rate depending on the state of stress. These parameters are defined in such a way that they can take care of concretes ranging from normal to high strength and, therefore, are a function of uniaxial compressive strength $f_{c}^{\prime}$ and initial elastic modulus $E_{o}$.

Since the focus of this study is limited to uniaxial behavior, therefore, $\alpha$ is considered to be zero, whereas, $\beta$ and $\gamma$ are considered to predict pre-and post-peak behaviour. Constitutive equation for materials that are damaged is expressed as (4)

$$
\varepsilon=\frac{\partial \Lambda(\sigma, \omega)}{\partial \sigma}
$$

Where $\varepsilon$ is strain, $\sigma$ is stress vector at principal direction and $\omega$ represents damage. For uniaxial compressive state, strain controlled incremental stress-strain relationship is expressed as (5) $d \sigma=\left(E_{o}(1-\beta \omega)^{4}-\frac{8\left(\beta^{2} \varepsilon_{1}^{2} E_{o}^{2}(1-\beta \omega)^{6}\right)}{\left(H+3 \beta^{2} \varepsilon_{1}^{2} E_{o}^{2}(1-\beta \omega)^{2}\right)}\right) d \varepsilon_{1}$

Main impact of replacing natural aggregates in concrete with RCA is on its compressive strength. Reduction in compressive strength of concrete has been observed as a result of increasing percentage replacement $[6-8,15,17]$. This impact on the concrete compressive strength $f_{c}{ }^{\prime}$ and $E_{0}$ has been incorporated in the model by defining them as a function of percentage replacement of natural coarse aggregates in concrete. The behaviour and relationship is discussed in subsequent sections.

\section{Prediction of RAC Compressive Strength}

From the published experimental data as shown in Table 1, a regression analysis was done to determine the relationship between $f_{c}^{\prime}$ of RAC and percentage replacement of natural aggregates with recycled aggregates that can be used in the proposed model. Proposed relationship for predicting compressive strength of RAC is given by (6) and has also been incorporated in the model

$f_{c}^{\prime}=\left(6.095 E-06 \times P_{r}^{2}-2.024 E-03 \times P_{r}+0.996\right) f_{c o n}^{\prime}$

where $f_{c}^{\prime}$ and $f_{c o n}^{\prime}$ are the cylindrical compressive strengths of RAC and NAC respectively, and $P_{r}$ is the percentage replacement of natural coarse aggregates by recycled aggregates

TABLE 1. Normalized Compressive Strength of RAC with Varying Replacement Percentage only.

\begin{tabular}{llllll}
\hline & \multicolumn{5}{l}{$\begin{array}{l}\text { Normalized Compressive } \\
\text { Strength }\end{array}$} \\
\hline Author /RCA (\%) & $\mathbf{0}$ & $\mathbf{3 0}$ & $\mathbf{5 0}$ & $\mathbf{7 0}$ & $\mathbf{1 0 0}$ \\
\hline Xiao [8] & 1 & 0.95 & 0.82 & 0.84 & 0.74 \\
Cai [14] & 1 & 0.85 & 0.96 & 0.84 & 0.85 \\
& 1 & 0.91 & 1.01 & 0.96 & 0.93 \\
& 1 & 0.97 & 1.02 & 0.99 & 0.96 \\
& 1 & 1.03 & 1.03 & 0.94 & 0.98 \\
Khan [15] & 1 & 0.90 & 0.82 & 0.86 & 0.74 \\
Bele'n [16] & 1 & & 0.84 & & 0.90 \\
& 1 & & 1.01 & & 0.94 \\
Xiao [17] & 1 & 0.90 & 0.97 & 0.78 & 0.82 \\
\hline
\end{tabular}

Comparison of normalized concrete compressive strength predicted by the proposed relationship for varying recycled aggregates replacement percentage with the experimental data used in regression is shown in Fig. 1. Good agreement can be noticed between predictions of (6) and the already published 
results. The general observation found in literature that the relative compressive strength reduces with the recycled aggregates replacement percentage increase is also reflected by predictions of proposed relationship. Furthermore, the declining trend of the concrete compressive strength which is more significant for case of concrete having recycled aggregates greater than $30 \%$ has been captured effectively by the proposed equation.

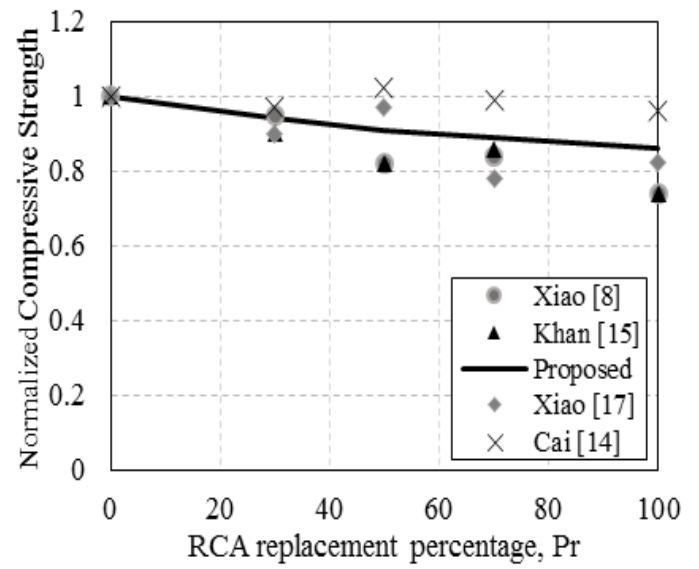

FIGURE 1. Comparison of predicted and experimental normalized concrete compressive strength

Predictions of proposed (6) are compared with the published experimental data that was not used while doing regression analysis to further validate the equation as shown in Fig. 2. It was observed that predicted values from proposed equation satisfies most of the published experimental results.

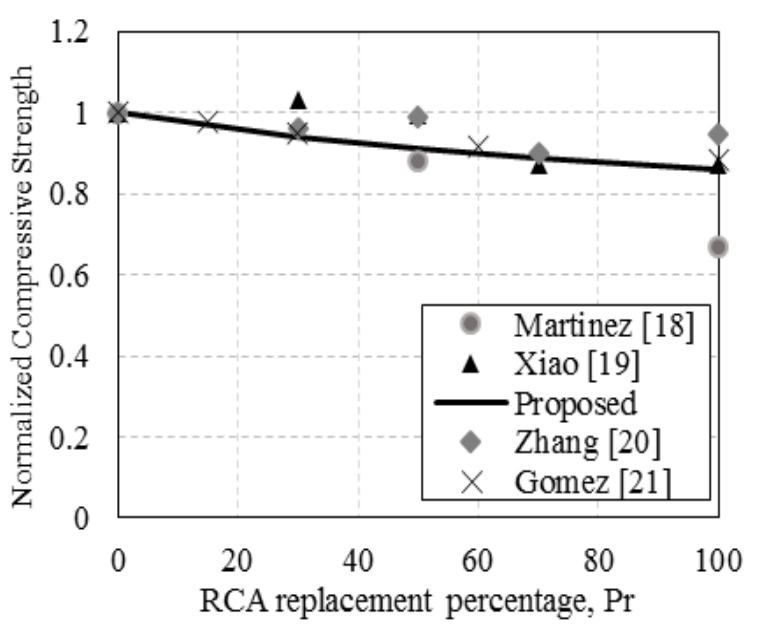

FIGURE 2. Comparison of predicted normalized concrete compressive strength with existing published data

\section{Prediction of Modulus of Elasticity of RAC}

Modulus of elasticity of concrete depends on aggregates and water-cement ratio. Since RAC absorbs more water as compared to natural aggregates, its modulus of elasticity is always on the lower side [22]. Modulus of elasticity is normally expressed as a function of $f_{c}^{\prime}$. Xiao [23], based on experimental data available, has proposed (7) to describe the relationship between modulus of elasticity and compressive strength of RAC using regression analysis. This equation was also used in the proposed model to predict the modulus for RAC.

$E_{o}=10^{5} /\left(2.9+\left(40.3 / f_{c}^{\prime}\right)\right)$

\section{RESULTS AND DISCUSSION}

\section{Proposed Constitutive Model Prediction for RAC}

Stress-strain response of RAC was predicted by using the Elasto-damage model proposed by [12] which was modified accordingly by modifying normal concrete compressive strength with RAC compressive strength as proposed in (6) and using modulus of elasticity relationship proposed by Xiao [23] for recycled aggregate concrete. Stress-strain response was simulated for the experimental data reported by Xiao [8]. It shows the predicted uniaxial stress-strain curves of concrete made with $0 \%$ (RC0), 30\% (RC-30), 50\% (RC-50), 70\% (RC-70), and $100 \%$ (RC-100) recycled aggregates. It can be seen that reduction in peak compressive strength with the increase in replacement percentage of the recycled aggregates has been captured effectively, however, no significant influence of percentage of recycled aggregates was observed on the post peak response with the increasing amount of the recycled aggregates. Figure 4 and 5 shows that the proposed model has the capability to capture the phenomenological behaviour of volumetric dilatation and Poisson's ratio degradation responsible for volumetric dilatation. Positive value shows contraction and negative value for volumetric strain shows dilatation in Fig. 4. 


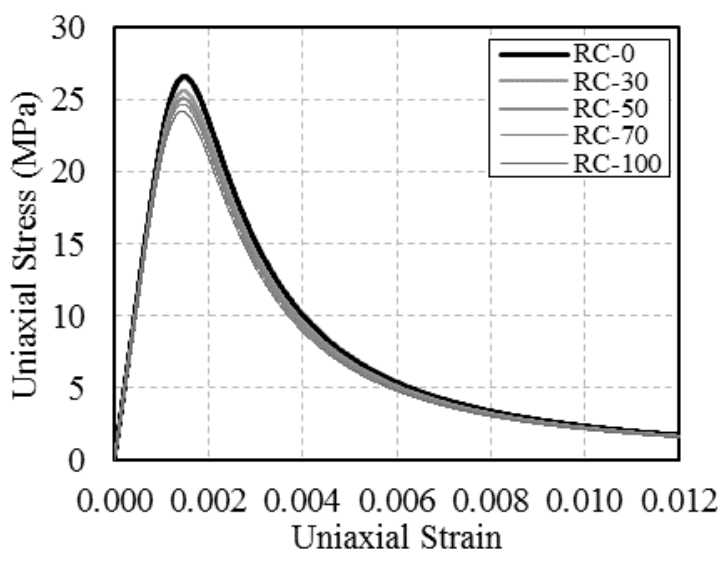

FIG. 3. Predicted uniaxial stress-strain curves for experimental data of RAC by Xiao [8]

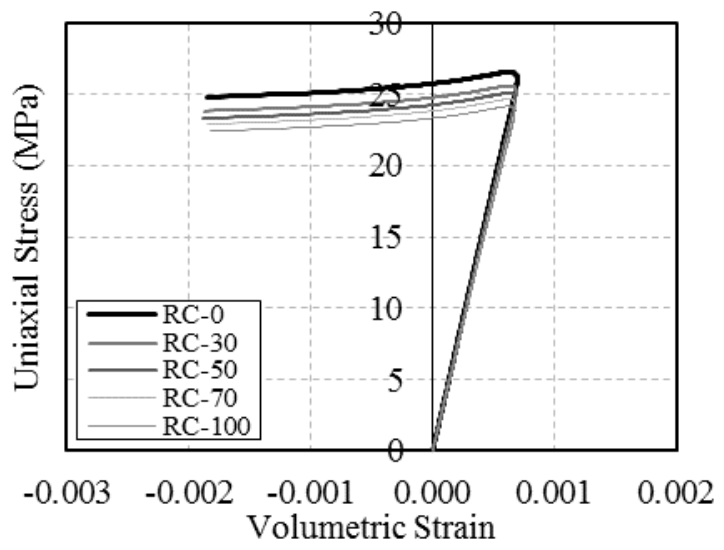

FIG.4. Volumetric dilatation of concrete with different percentages of recycled aggregates under uniaxial compression

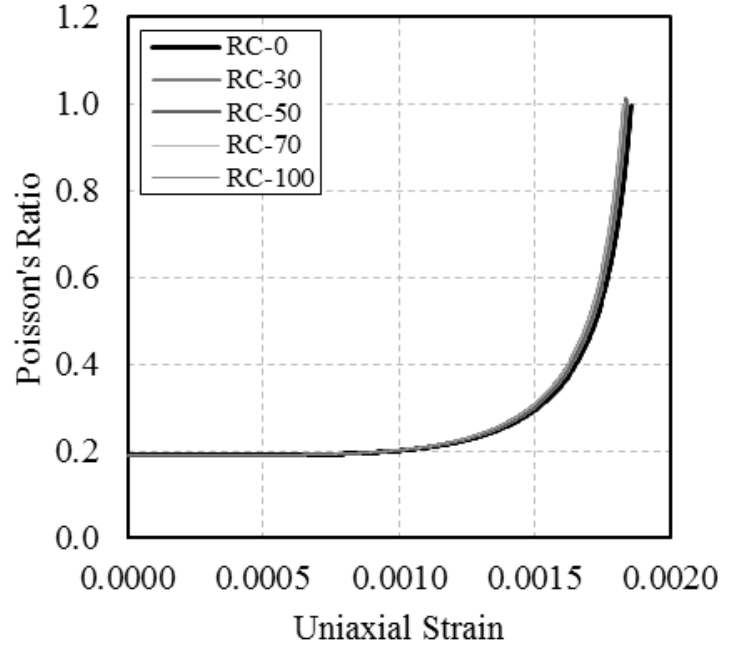

FIG. 5. Apparent Poisson's ratio of concrete with different percentages of recycled aggregates under uniaxial compression

\section{Comparison with Experimental Data and Existing Models}

Predictions of the proposed model were compared with experimental data and existing models of [8]. Modulus of elasticity was varied in the proposed model to see its impact on the stress-strain curves predicted by the model. Figure 6 shows stress-strain curves for four replacement ratios of RCA, where "Predicted [8]" represents model proposed by [8], "Exp. [8]" represents experimental stress-strain curves reported by [8], "Proposed-X" represents proposed model with modulus of elasticity values taken from experimental results by [8] and "Proposed-C" represents proposed model with modulus of elasticity calculated by equation proposed by [11] which was a modification of Chinese Code GB50010 [24]. It was observed that pre-peak behavior was found to be similar for all the stressstrain curves presented herein. Furthermore, it was also observed that the predicted stress-strain curves are in good agreement with the existing model and experimental data of Xiao [8]. Stiffer post peak response is observed in proposed model while using modified Chinese code equation for modulus of elasticity as compared to Proposed-X model. 


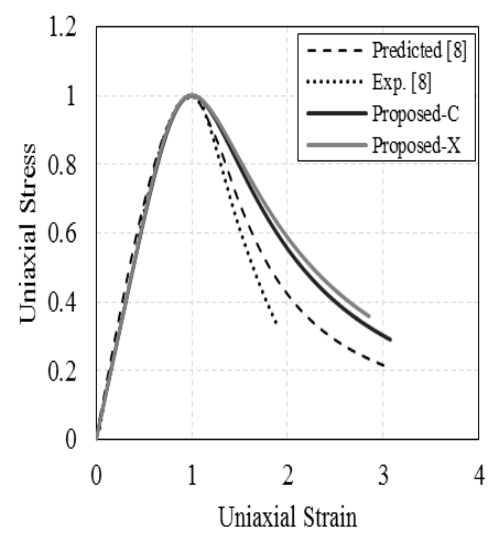

(a)

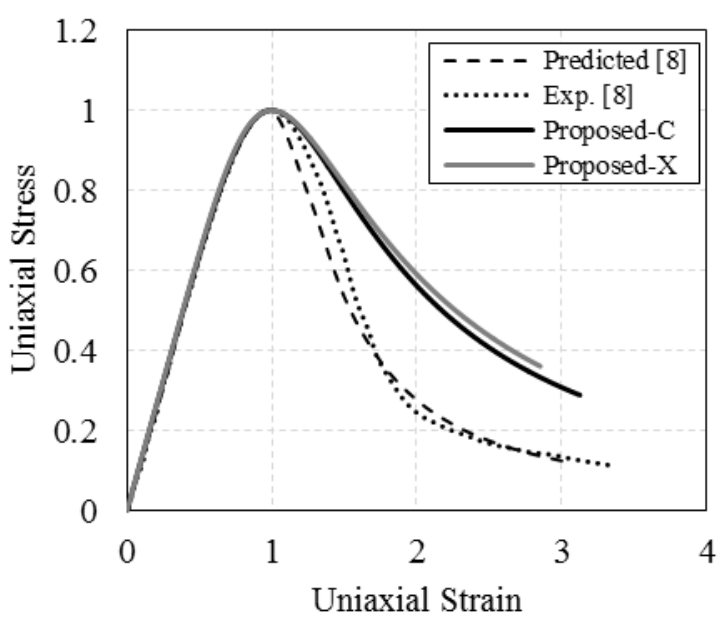

(c)

d)

FIGURE 6. Comparison of normalized stress-strain curves for a) $P_{r}=30 \%$ b) $P_{r}=50 \%$ c) $P_{r}=70 \%$ d) $P_{r}=100 \%$

\section{CONCLUSIONS}

From the investigation conducted in this study of an elasto-damage constitutive model modified to predict the behaviour of RAC under uniaxial compression are presented in this paper in the form of actual and normalized stress-strain curves, volumetric dilatation, Poisson's ratio degradation. Predicted stress-strain curves, actual and normalized, have showed close agreement with the available experimental data and existing models. The model was shown to be capable of capturing salient features of concrete such as strain softening and volumetric

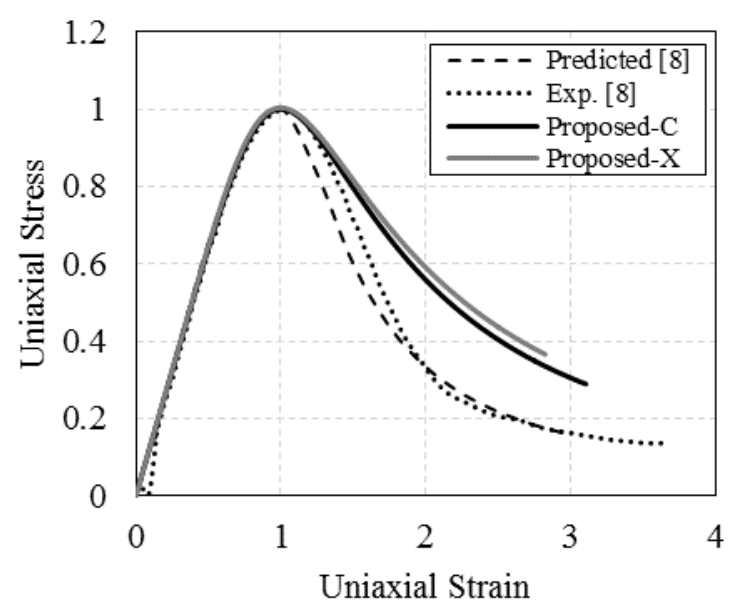

(b)

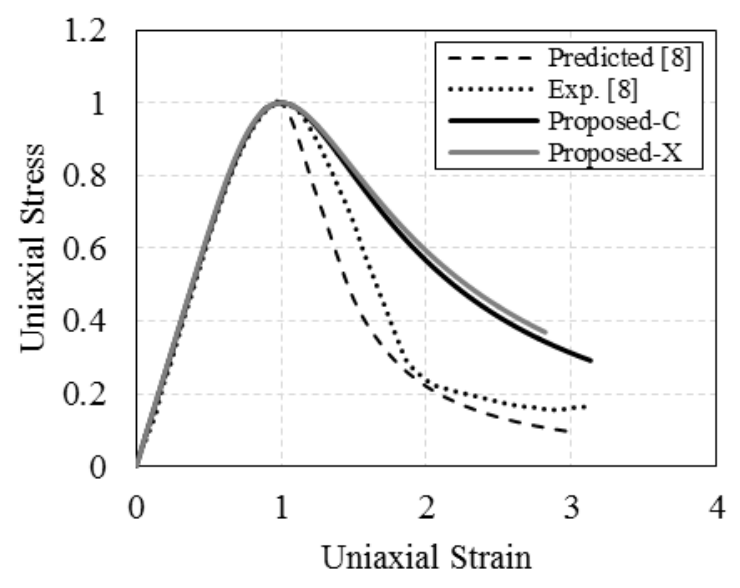

dilation. Furthermore, it was also observed that prepeak behavior was found to be similar for all the stress-strain curves presented herein. Furthermore, it was also observed that the predicted stress-strain curves are in good agreement with the existing model and experimental data of Xiao [8]. More biaxial and triaxial data will be used to propose a more general model capable of handling multiaxial states of stress

\section{ACKNOWLEDGMENT}

Support provided by Pakistan Science Foundation (PSF) through Joint Research Project between NSFC 
and PSF (PSF/NSFC-Eng/S-NED (05)) in the pursuit of this work is hereby acknowledged by the authors

\section{REFERENCES}

[1] UNEP; ISWA. Global Waste Management Outlook; United Nations Environment Programme: Vienna, Austria, (2015).

[2] P. Thongkamsuk, K. Sudasna, and T. Tondee, Energy Procedia, 138, 411-416 (2017).

[3] A. Turkyilmaz, M. Guney, F. Karaca, Z. Bagdatkyzy, A. Sandybayeva, and G. A. Sirenova, Sustainability, 11, 1593-1609 (2019).

[4] M. Etxeberria, AR. Mari, and E. Vázquez, Materials and structures, 40, 529-41, (2007).

[5] M. Sofi, P. Mendis, E. Lumantarna, D. Baweja, and J. Portella, International Conference on Sustainable Built Environment (Kandy, Sri Lanka, ICBSE-2012).

[6] J. Xiao, J. B. Li, and J. Huang , Chinese J Building Mater, 9, 297-301 (2006).

[7] J. Xiao, and Y. Lan, Chinese J Building Mater, 8, 154-158 (2006).

[8] J. Xiao, J. B. Li, and C. Zhang, Cement and Concrete Research, 35, 1187-1194 (2005).

[9] T. Du, W. Wang, Z. Liu, H. Lin, and T. Guo, Journal of Wuhan University of TechnologyMater. Sci. Ed., 25, 862-865 (2010).

[10] P. Folino, and H. Xargay, Construction and Building Materials, 56, 21-31 (2014).

[11] X. Hu, Q. Lu, and S. Cheng, Hindawi: Advances in Materials Science and Engineering, 2019, 2982195 (2019).

[12] AU. Khan, and T. Zahra, Journal of Mechanics of Continua and Mathematical Sciences, 14, 7-26 (2019).

[13] W. Suaris, C. Ouyang, and VM. Fernando, Journal of engineering mechanics, 116, 10201035 (1990).

[14] H. Y. Cai, M. Zhang, and LB. Dang, Applied Mechanics and Materials, 174, 1277-1280 (2012).

[15] AU Khan, M. S. Khan, S. Fareed, and J. Xiao, Arabian Journal for Science and Engineering, 45, 3611-3622 (2020).

[16] G. F. Belén, M. A. Fernando, C. L. Diego, and S. P. Sindy, Construction and Building materials, 25, 2335-2342 (2011).

[17]Xiao J., Huang Y., Yang J., and Zhang C., Construction and Building Materials, 26, 591603 (2012).

[18] I. Martínez-Lage, F. Martínez-Abella, C. Vázquez-Herrero, and JL. Pérez-Ordóñez, Construction and Building Materials, 37,171-176 (2012).

[19] J. Xiao, Y. Fan, and M. Tawana, Structural Concrete, 14, 168-175 (2013).

[20] LS. Zhang, XL. Zhang, and GX. Yan, Journal of Zhengzhou University (Engineering Science), 27, 18-23 (2006).

[21] JM. Gómez-Soberón, Cement and concrete research, 32, 1301-1311 (2002).
[22] M. S. Brett, Shrinkage and Modulus of Elasticity in Concrete with Recycled Aggregates, Doctoral dissertation (MSEE), California Polytechnic State University, 2011.

[23] J. Xiao , J. B. Li, and C. Zhang, Materials and structures, 39, 655-64 (2006).

[24] Standard C. GB 50010-2010. Code for design of concrete structures (2010).

\section{Creative Commons Attribution License 4.0 (Attribution 4.0 International, CC BY 4.0)}

This article is published under the terms of the Creative Commons Attribution License 4.0 https://creativecommons.org/licenses/by/4.0/deed.en_US 